\title{
Experimental and CFD Investigation of a Modified Uneven-Span Greenhouse Solar Dryer in No-Load Conditions under Natural Convection Mode
}

\author{
Abderrahman Mellalou $\mathbb{D}^{1},{ }^{1}$ Walid Riad, ${ }^{1}$ Salma Kaotar Hnawi, ${ }^{1}$ Abdelaziz Tchenka, \\ Abdelaziz Bacaoui, ${ }^{2}$ and Abdelkader Outzourhit ${ }^{1}$ \\ ${ }^{1}$ Laboratory of Materials for Energy and Environment (LaMEE), Faculty of Sciences Semlalia, University Cadi Ayyad, \\ Marrakech 40000, Morocco \\ ${ }^{2}$ Laboratory of Applied Chemistry (LCA), Faculty of Sciences Semlalia, University Cadi Ayyad, Marrakech 40000, Morocco \\ Correspondence should be addressed to Abderrahman Mellalou; abderrahman.mellalou@gmail.com
}

Received 26 March 2021; Revised 16 June 2021; Accepted 14 July 2021; Published 29 July 2021

Academic Editor: Juan M. Coronado

Copyright (C) 2021 Abderrahman Mellalou et al. This is an open access article distributed under the Creative Commons Attribution License, which permits unrestricted use, distribution, and reproduction in any medium, provided the original work is properly cited.

\begin{abstract}
An uneven-span modified greenhouse dryer was constructed and tested in no-load conditions under natural convection mode under the weather conditions of Marrakech, Morocco, for two distinct days. Moreover, a CFD evaluation of the uneven-span greenhouse dryer was performed as tool to visualize the air temperature distribution inside the dryer. For validating the CFD model, the temperature variations along the hours of the day were compared to the experimental results. A good agreement is obtained between the computed and measured inside air temperature with a difference not exceeding $8.46^{\circ} \mathrm{C}$, with a correlation coefficient $(r)$ and root mean square percentage deviations $(e) 0.94$ and 8.17 , respectively. Furthermore, the maximum inside air temperature was measured to be $56^{\circ} \mathrm{C}$ and $52^{\circ} \mathrm{C}$ while the minimum inside relative humidity was measured to be $17 \%$ and $12 \%$, for day-1 and day-2, respectively. The benefice of using asphalt as a floor covering material was revealed as an efficient way to heat the inside air at low solar radiations. The performances of the dryer were evaluated by the percentage of net heat gain variation as a way to validate the effectiveness of the dryer. This latter is found to be equal to $46 \%$ and $48 \%$ for the two days, respectively.
\end{abstract}

\section{Introduction}

Solar energy has received significant attention as an efficient, promising, durable, cost-effective, and environmentally friendly source of energy. The potential of solar energy is well established in a variety of fields, such as material treatment to produce manufactured goods, desalination, biomass conversion, refrigeration, food processing, space heating, domestic water heating, and biomass valorization using thermochemical methods and in the agricultural and drying fields [1]. The world's drying and agriculture industry consumed 198 million tons of oil equivalents in 2016, including $92.42 \%$ produced from fossil fuels [2]. Therefore, solar energy is a promising and environmentally friendly alternative to fossil fuels in the agricultural and drying fields in order to mitigate global warming associated with the extensive use of fossil fuels in these fields.

Different types of solar dryers have been designed and studied in order to increase the solar dryer efficiency and consequently reduce the drying costs. Solar drying can be categorized into direct and indirect processes, which in their turn can use either forced or natural circulation. Moreover, mixed and hybrid solar drying combine direct and the indirect processes. An additional heat source for air preheating or heating is used in the latter process $[1,3]$. Fudholi et al. [4] used a hybrid solar drying system for the investigation of the thin-layer drying kinetics of salted silver jewfish. The hybrid system is composed besides the air solar collector of a diesel burner as a heat back up in order to provide continuous heat as required by the drying chamber. Chouicha et al. 
[5] studied the drying of sliced potatoes using a modified solar dryer with electrical resistance powered by a number of photovoltaic panels. The drying time was thus reduced by one hour and a half. Lopez-Vidana et al. [6] evaluated the thermal and drying efficiency of three configurations of a hybrid solar-gas dryer. The dryer is composed of a solar collector and an auxiliary LPG (liquid propane gas) combustion heater.

On the other hand, greenhouse drying is one of the most effective drying methods as it can combine all the abovementioned techniques (direct, indirect, hybrid, and mixed). The greenhouse structure offers protection and uniform drying rate and yields a very high quality product $[1,7,8]$. Several greenhouse shapes have been studied [2, 7-9], namely, even-span, uneven-span, elliptical, and vinery. Chen et al. [2] evaluated the global solar radiation captured at different latitudes by six greenhouse shapes. They found that the sawtooth shape and the east-west orientation captured the highest amount of global solar radiation in winter at all latitudes. Çakır and Şahin [7] made a comparative study to determine the best greenhouse shape, orientation, type, length-to-width ratio, and position for Bayburt-Turkey. They concluded that the greenhouse roof shape is one of the main effective factors on solar energy gaining rates. Furthermore, the air and temperature distribution within the greenhouse dryer affects its performances. Indeed, as inadequate distributions of both air and temperature cause nonuniform drying, which yields to a low-quality product. Sánchez et al. [10] experimentally studied the effect of rotating trays on the drying performance of tomato slices. It was found that the use of tray rotation reduced significantly the temperature variation between the trays from 2 to $0.2^{\circ} \mathrm{C}$, thereby enhancing the overall drying efficiency and the product quality.

The implementation of computational fluid dynamics CFD in the greenhouse drying field has received significant attention. Indeed, CFD is an efficient tool for system evaluation as it offers the ability to perform a range of parametric studies for system optimization. Moreover, the effect of different parameters on the drying process can be easily performed by means of CFD tools. In addition, the evaluation of air, temperature, and moisture distribution inside the greenhouse dryer under different climatic conditions (irradiance, ambient temperature, humidity, and wind speed) will help in improving the design of the greenhouse shape and the air treatment and conditioning systems. Noh et al. [11] used ANSYS Fluent to simulate and analyze the effect of product arrangements on the temperature and airflow distribution inside the drying chamber of a newly developed solar dryer. They found that the zigzag pallet arrangement produced higher and more uniform air flow compared to the straight pallet arrangement inside the drying chamber. Babu et al. [12] evaluated theoretically the air flow distribution in different drying chamber configurations in the tray dryer using CFD tools. Their work was based on looking for the best tray configuration which ensures the minimum pressure drop, the maximum mass transfer rate, and the most uniform air temperature and airflow distribution. Khanlari et al. [13] evaluated the thermal performance of a greenhouse dryer assisted by a tube-type solar air heater numerically by the mean of the ANSYS Fluent software. Their empirical and numerical simulation results are found to be in good agreement. Demissie et al. [14] employed CFD for the prediction of the air flow and temperature distribution inside an indirect food dryer. They found that the maximum average temperature difference between the CFD simulation and measurement was $4.3^{\circ} \mathrm{C}$. Jia et al. [15] modeled the heat transfer of greenhouse underfloor heating system by the mean of the Fluent software. The effect of several important factors (pipe diameter, pipe spacing, laying depth, and supplied water temperature and flow rate) on the temperature distributions within the greenhouse system was evaluated. Vivekanandan et al. [9] made an experimental and CFD investigation of six shapes of solar greenhouse dryers under no-load conditions. They found that the experimental values are in good agreement with CFD values with and error of $15 \%$. Tarigan [3] simulated a back-up heater (biomass burner) in a solar agricultural dryer with back-up biomass burner and thermal storage by means of CFD simulation. The temperature and air flow distribution patterns were visualized. The results showed an average drying air temperature in the drying chamber of $56^{\circ} \mathrm{C}$, which is suitable for agriculture product drying.

To our knowledge, no author had evaluated the performances of a modified uneven-span greenhouse dryer in noload conditions under natural convection mode taking both paths of CFD simulation and experimental evaluation. Vivekanandan et al. [9] only evaluated the air temperature distribution inside six different types of greenhouse dryers by the mean of ANSYS Fluent, whereas Chauhan and Kumar [8] conducted only an experimental study of the performances of a greenhouse dryer in no-load conditions under natural convection, and Prakash and Kumar [16] studied only the effects of heat loss and the instantaneous thermal loss efficiency factor on the performances of a modified greenhouse dryer.

In the present work and as a novelty, two different ways to evaluate the performances of a greenhouse dryer were considered, namely, an experimental and a CFD study. The computational fluid dynamic package (ANSYS Fluent software) was used to evaluate the performance of an uneven-span greenhouse dryer at no-load conditions under the meteorological conditions of Marrakech-Morocco. This greenhouse dryer is intended to be used for drying agricultural products with high moisture content. The key features of the greenhouse dryer system in this study are the roof inclination angle $12^{\circ}$ and the floor covering material in order to capture the maximum of solar radiation and enhance its reradiated fraction, by consequence increasing the air temperature within the greenhouse dryer.

\section{Materials and Methodology}

2.1. Description of the Solar Greenhouse Dryer. The greenhouse dryer was constructed at the Faculty of Sciences Semlalia, Marrakech $\left(31.6295^{\circ} \mathrm{N}, 7.9811^{\circ} \mathrm{W}, 466 \mathrm{~m}\right)$, in the framework of the BIORESOL project. It consists of an uneven-span structure made of stainless iron frame mounted on a concrete floor and glazed with polycarbonate sheets of 


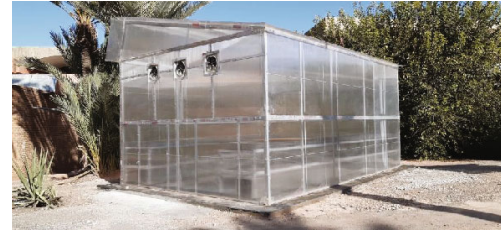

(a)

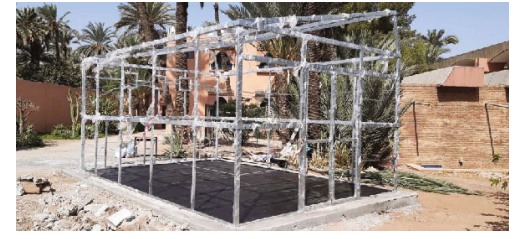

(b)

Figure 1: Photograph of modified greenhouse dryer structure (a) without and (b) with polycarbonate sheet.

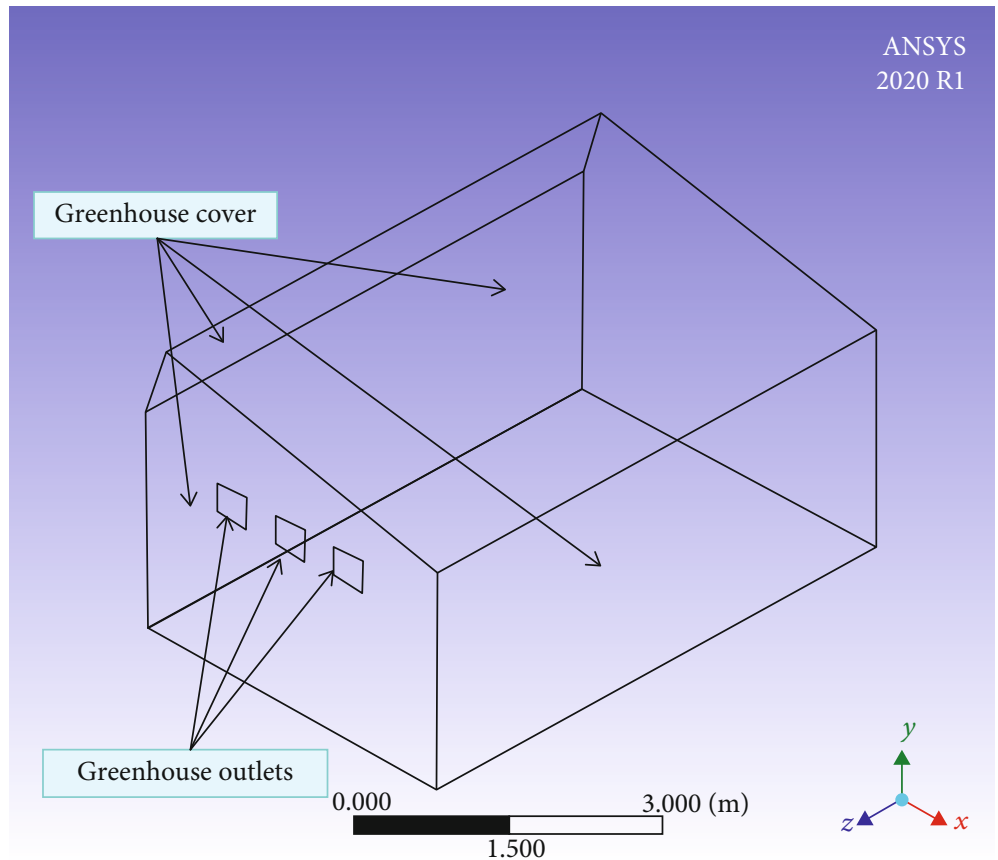

FiguRE 2: 3D geometric model of the uneven-span greenhouse dryer.

$6 \mathrm{~mm}$ thickness. The length, width, and height of the greenhouse dryer were, respectively, $6 \mathrm{~m}$ by $4 \mathrm{~m}$ by $3.5 \mathrm{~m}$. The dryer is equipped with 3 fans fixed at the outlets to reject the moisture air to the surrounding environment. The greenhouse dryer has a roof inclination angle of $12^{\circ}$ and positioned in an east-west orientation in order to maximize available solar energy throughout the year as shown in Figure 1(a). Moreover, the dryer floor was covered with asphalt layer of thickness $(4 \mathrm{~mm})$ to enhance the reradiated energy and consequently increase the air temperature within the greenhouse dryer (Figure 1(b)).

2.2. Instrumentation. The solar radiation was measured on the horizontal plane using a CM5 pyranometer (KIPP \& ZONEN, Holland). The ambient and indoor temperatures and relative humidity were measured using a wellcalibrated digital thermohygrometer (BK Precision Model 720 Humidity/Temp Meter). The measurement of the air velocity was made by HoldPeak HP-866B Digital Anemometer with a wind speed range from 0.03 to $30 \mathrm{~m} / \mathrm{s}$.

2.3. CFD Simulation. In the present study, the ANSYS software was used as a CFD tool in order to evaluate the temperature distribution inside the uneven-span greenhouse dryer and trying to reveal the importance of the floor covering material in enhancing the performances of the dryer. The numerical simulation results were compared with experimental ones in the objective of developing a CFD model translating the behavior of the dryer at no-load conditions and under natural convection, hence relying on this model as way to facilitate the improvement of the thermal performances of the modified greenhouse dryer.

2.3.1. Uneven-Span Greenhouse Structure Modeling. In order to generate the uneven-span greenhouse dryer, the ANSYS Workbench Design Modeler was used. The built geometry was drawn according to the dimensional characteristics of the experimental greenhouse dryer. The $3 \mathrm{D}$ geometric model is presented in Figure 2. The use of a 3D model enhances the accuracy of the results and allows an efficient evaluation of the drying system. The mesh step was made by the ANSYS Fluent Mesh program. The tetrahedron structure meshing mode was adopted. The numbers of cells and elements considered were 381,440 and $1,577,727$, respectively, in order to achieve favorable CPU computation time, with more accurate and reliable results. The maximum and minimum orthogonal quality and skewness associated values were 0.16982-0.99798 and 0.00020978-0.83018, respectively. 
2.3.2. Governing Equations. The CFD simulation was evaluated taking in consideration natural convection inside the uneven-span greenhouse dryer. In this case, the Boussinesq model was adopted where the air density $\rho$ is given by the following equation [17]:

$$
\rho=\rho_{\text {ref }}\left[1-\beta\left(T-T_{\text {ref }}\right)\right]
$$

where $\beta$ is the thermal expansion coefficient $\left(K^{-1}\right), T$ is the temperature, and $T_{\text {ref }}$ is the operating temperature [17].

The radiative transfer equation was modeled by the discrete ordinate (DO) radiation model. It has the advantage to solve radiative transfer equation for a finite number of discrete solid angles, each associated with a fixed vector direction, at semitransparent walls (e.g., glass, polycarbonate, and polyethylene). In the DO model, the radiative transfer equation in the direction $\vec{s}$ is given by the following [17]:

$$
\begin{aligned}
& \nabla \cdot(I(\vec{r}, \vec{s}) \vec{s})+\left(\alpha+\sigma_{s}\right) I(\vec{r}, \vec{s}) \\
& \quad=a n^{2} \frac{\sigma T^{4}}{\pi}+\frac{\sigma_{s}}{4 \pi} \int_{0}^{4 \pi} I\left(\vec{r}, \overrightarrow{s^{\prime}}\right) \varnothing\left(\vec{s} \cdot \overrightarrow{s^{\prime}}\right) d \Omega^{\prime},
\end{aligned}
$$

where $I$ is the intensity, $\vec{r}$ is the position vector, $\overrightarrow{s^{\prime}}$ is the scattering direction vector, $\sigma$ is the Stefan-Boltzmann constant, $\alpha$ is the absorption coefficient of air, $\sigma_{s}$ is the scattering coefficient, $n$ is the refractive index of air, $\varnothing$ is the phase function, and $\Omega^{\prime}$ is the solid angle (radian).

The basic governing equations of fluid flow and heat transfer are the Navier-Stokes equations, which are derived from the basic mass conservation and continuity equations applied to fluid properties. These equations are as follows [17]:

(i) Continuity equation

$$
\frac{\partial \rho}{\partial t}+\nabla(\rho \vec{v})=0
$$

(ii) Momentum equation

$$
\frac{\partial}{\partial t}(\rho \vec{v})+\nabla \cdot(\rho \vec{v} \vec{v})=-\nabla \cdot p+\nabla \cdot \vec{\tau}+\rho \vec{g}+\vec{F}
$$

(iii) Energy conservation equation

$$
\frac{\partial}{\partial t}(\rho E)+\nabla \cdot(\vec{v}(\rho E+p))=\nabla(\lambda \nabla T)+S_{h}
$$

2.3.3. Heat Transfer Coefficients. The convective heat transfer coefficient $(h)$ used to evaluate the thermal behavior between the greenhouse cover and the ambient air is given by the following [18]:
TABLE 1: Maximum uncertainty associated to instruments.

\begin{tabular}{lc}
\hline Parameter & Accuracy \\
\hline Air temperature & $\pm 0.7^{\circ} \mathrm{C}$ \\
Air humidity & $\pm 2.5 \%$ \\
Air velocity & $\pm 5 \%$ \\
Solar irradiance & $\pm 1 \%$ \\
\hline
\end{tabular}

$$
h=2.8+3 V_{w}
$$

where $V_{w}$ is the wind velocity.

In addition, the following expression for the sky temperature $\left(T_{\text {sky }}\right)$ was used to evaluate the radiative transfer between the sky and the greenhouse dryer cover:

$$
T_{\text {sky }}=0.0552 T_{\text {ambiant }}^{1.5} \text {, }
$$

where $T_{\text {ambiant }}$ is the air ambient absolute temperature.

2.3.4. Model Validation. To compare the experimental results with the simulated ones, the root mean square percentage deviation $(e)$ and the correlation coefficient $(r)$ were calculated, by using the following equations $[19,20]$ :

$$
\begin{aligned}
& e=\sqrt{\frac{\sum\left(\left[X_{i}-Y_{i} / X_{i}\right] * 100\right)^{2}}{N}}, \\
& r=\frac{N \sum X_{i} Y_{i}-\sum X_{i} * \sum Y_{i}}{\sqrt{N \sum X_{i}^{2}-\left(\sum X_{i}\right)^{2}} \sqrt{N \sum Y_{i}^{2}-\left(\sum Y_{i}\right)^{2}}},
\end{aligned}
$$

where $N, X_{i}$, and $Y_{i}(i=1$ to $N)$ stand for the number of values, the calculated values (obtained by the ANSYS Fluent simulation), and the experimental values, respectively.

A positive value of $r$ indicates a positive linear relationship, while a negative one indicates a negative linear relationship. On the other hand, $r=0$ implies the absence of a linear relationship between the two variables.

2.3.5. Evaluation of the Experimental Uncertainty. The experimental investigation involved the measurement of quantities like the air temperature, humidity, and velocity besides the solar irradiance. The general expression for the overall uncertainty estimation for a parameter $R$ due to the combined effect of different measured variables is given as follows [21]:

$$
\delta R=\sqrt{\sum_{i=1}^{N}\left(\left(\delta R / \delta x_{i}\right) \delta x_{i}\right)^{2}} .
$$

The maximum relative uncertainties associated to the various instruments according their specifications are given in Table 1.

Using these values and equation (9), the uncertainties associated with the heat transfer coefficient $(h)$, the sky temperature, the percentage of net heat gain with respect to 


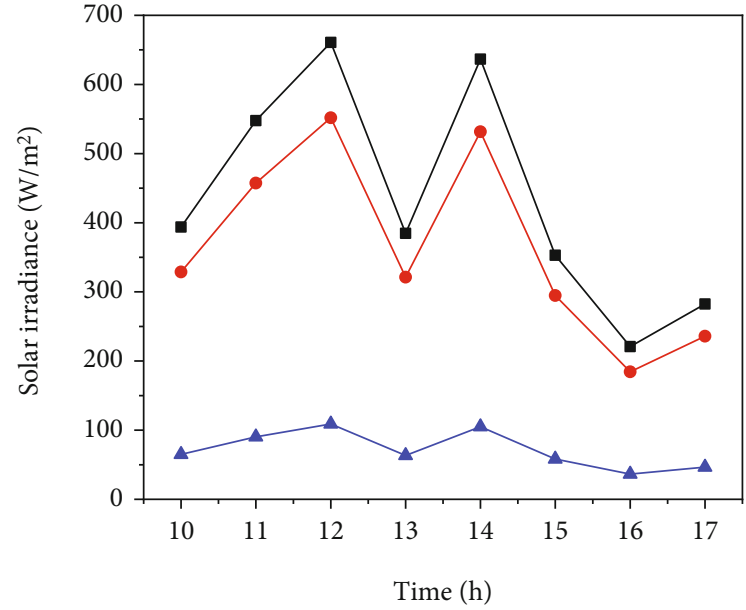

(a)



(b)

Figure 3: Variation of solar insolation with time of (a) day-1 and (b) day-2.

ambient temperature $\left(Q_{g}\right)$, and instantaneous thermal loss efficiency factor $\left(\eta_{i}\right)$ are, respectively $\pm 0.34 \mathrm{~W} / \mathrm{m}^{2} / \mathrm{K}$, $\pm 0.31 \mathrm{~K}, \pm 1.51$, and \pm 0.07 .

\section{Results and Discussions}

3.1. Experimental Results. In this study, the experimental measurements were conducted in an uneven-span greenhouse dryer under no-load conditions at different days from October to December 2020 at the Faculty of Sciences Semlalia (Marrakech-Morocco). The considered period was chosen in order to evaluate the solar dryer performances under these conditions. Two typical days of this period were used for this study, which are 28/10/2020 (day-1) and 24/11/2020 (day-2). The solar irradiance of the first day has an intermittent character (Figure 3(a)), while the second day has a clear sky (Figure 3(b)). The highest irradiance was found to be equal to $661 \mathrm{~W} / \mathrm{m}^{2}$ and $647 \mathrm{~W} / \mathrm{m}^{2}$ for day-1 and day-2, respectively.

3.1.1. Ambient Parameters. The air temperature, relative humidity, and wind velocity were recorded every hour during each day from $10 \mathrm{~h}: 00$ to $17 \mathrm{~h}: 00$. Figure 4(a) presents the hourly variation of the ambient temperatures associated to day-1 and day-2. The average ambient temperature on the first and second day was $25^{\circ} \mathrm{C}$ and $24^{\circ} \mathrm{C}$, respectively. Figure 4(b) shows the evolution of the ambient relative humidity for the two days. The average values are, respectively, $32 \%$ and $42 \%$ for day- 1 and day-2. Figure 4 (c) shows that the wind velocity varied from 0.10 to $1.35 \mathrm{~m} / \mathrm{s}$ and from 0.4 to $1.8 \mathrm{~m} / \mathrm{s}$ for day- 1 and day-2, respectively.

3.1.2. Evolution of the Air Temperature and Humidity within the Uneven-Span Greenhouse. Figure 5 presents the variation of the most important parameters in the drying process, namely, the inside temperature and relative humidity. These two parameters depend strongly on the climatic conditions of the site and on the greenhouse shape and construction materials [22]. The inside temperature should be always high ranging between $40^{\circ} \mathrm{C}$ and $80^{\circ} \mathrm{C}$, and the inside relative humidity should always be low, in order to get an efficient drying process $[2,8,9,19]$. The air temperature within the uneven-span greenhouse dryer follows the global solar radiation variation (Figure 5(a)). It varied from 36 to $50^{\circ} \mathrm{C}$ and from 30 to $56^{\circ} \mathrm{C}$ for day-1 and day-2, respectively. For both days, the maximum value of inside air temperature was recorded at $14 \mathrm{~h}: 00$. Moreover, the average air temperature within the greenhouse dryer was $45.70 \%$ and $48.71 \%$ higher than the ambient temperature for day- 1 and day-2, respectively. The solar radiation intensity and wind velocity variation along the day are the factors behind the evolution of the inside temperature. The wind velocity is directly related to the convective heat transfer between the greenhouse dryer cover and the air ambient temperature, as illustrated in equation (6).

Figure 5(b) illustrates the variation of the inside air relative humidity as a function of time. Relative humidity decreases over time during the first half of the day while the opposite was true during the other half of the day. The reduction in the relative humidity compared to the ambient relative humidity was by $51.83 \%$ and $49.31 \%$ for day- 1 and day-2, respectively. Furthermore, as the air temperature increases, the air relative humidity within the uneven-span greenhouse decreases.

3.2. CFD Results. The main objective of the simulation study was to develop a CFD model of the studied greenhouse dryer to validate it with the experimental data. The simulations will enable to visualize and evaluate the air temperature distribution within the greenhouse dryer. The temperature contours 


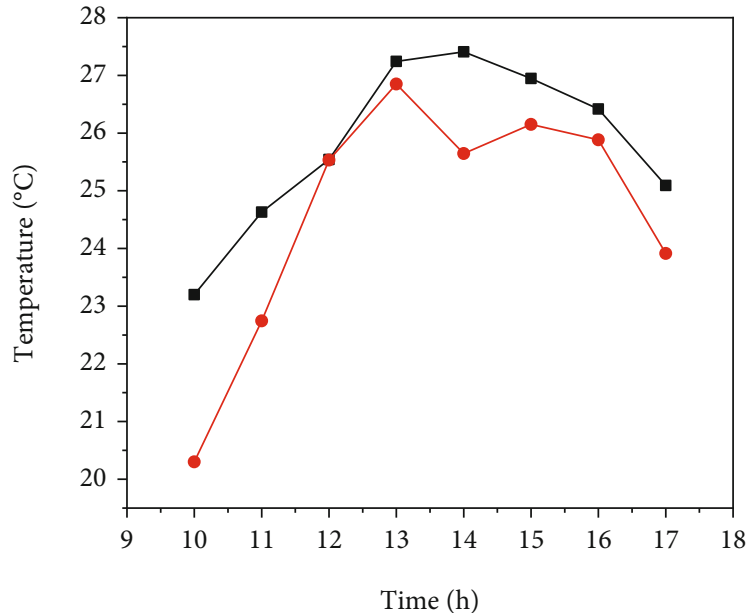

(a)



(b)

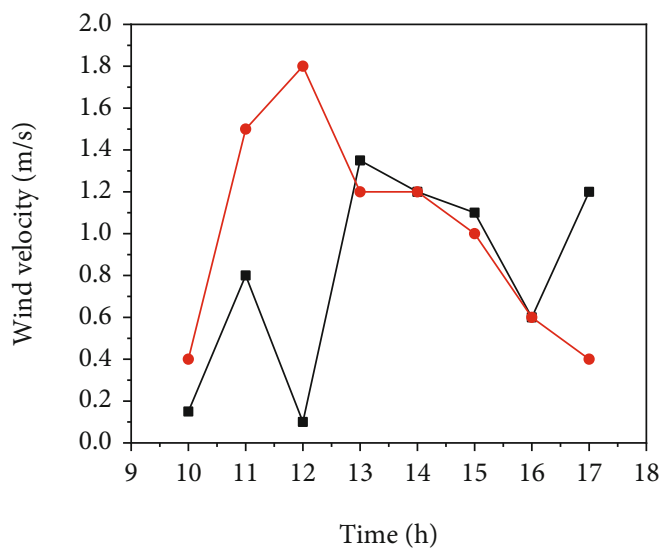

- Day-1

- Day-2

(c)

FIGURE 4: Variation of air (a) ambient temperature, (b) ambient relative humidity, and (c) wind velocity with time of day-1 and day-2.
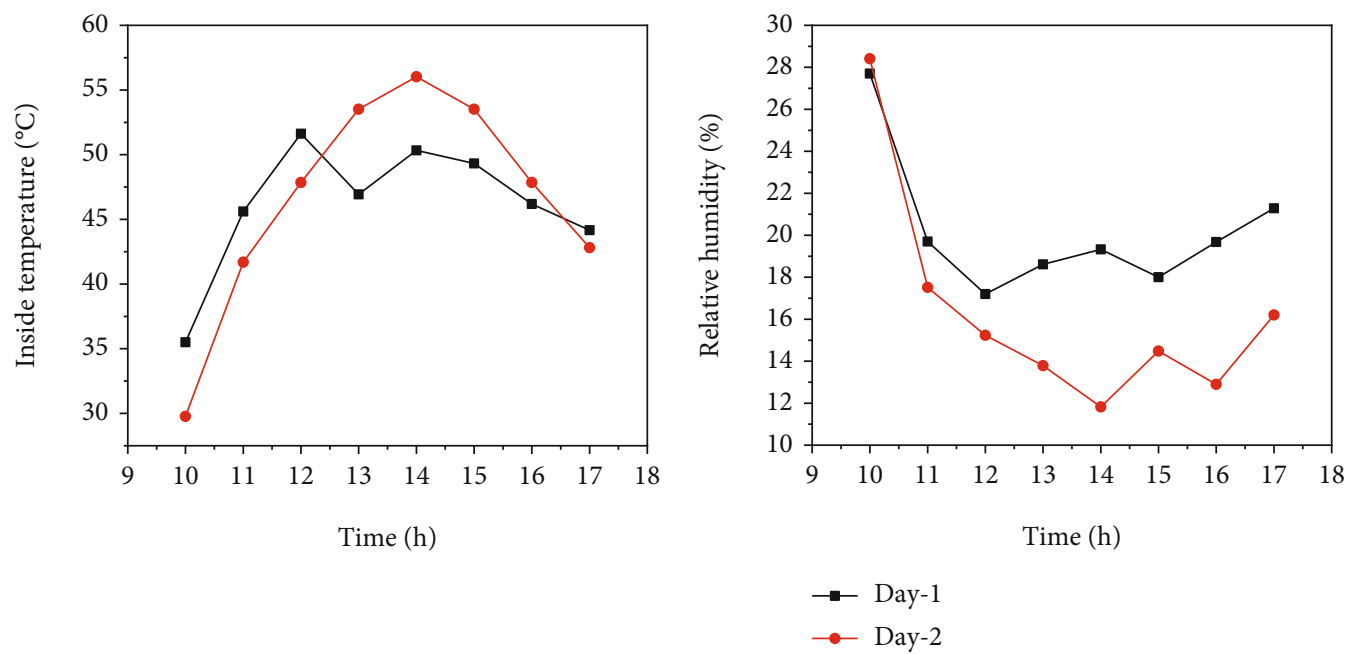

(a)

(b)

FIgURE 5: Variation of air inside (a) temperature and (b) relative humidity with time of day-1 and day-2. 


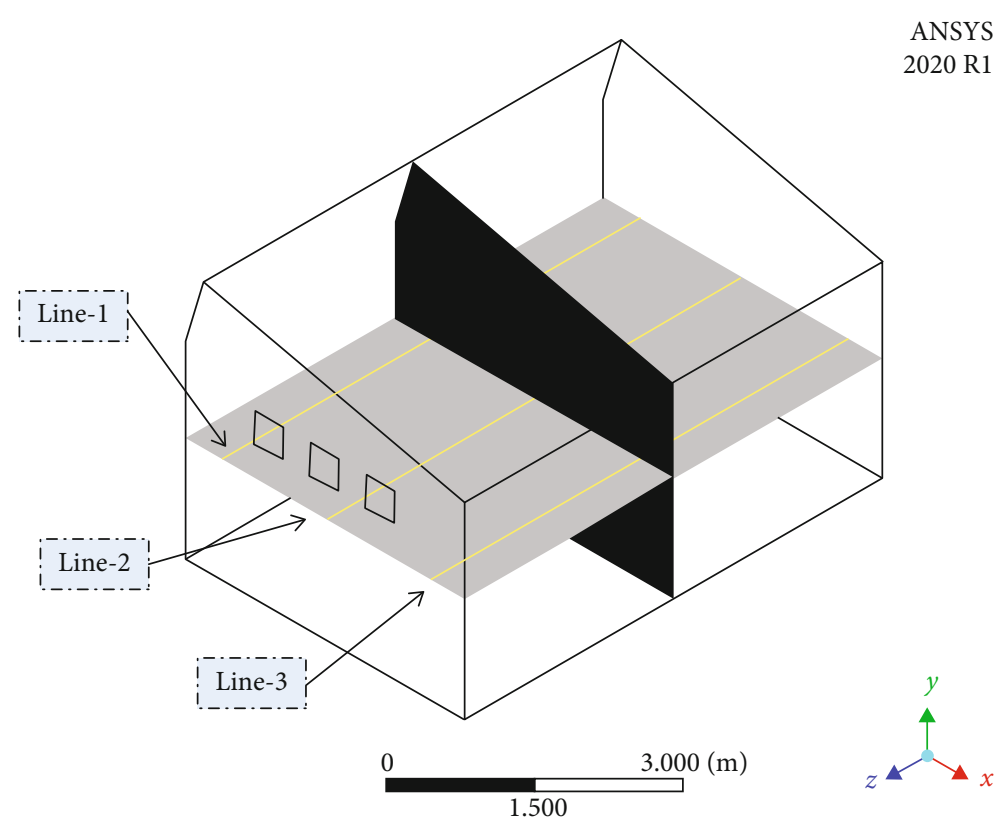

FIGURE 6: Selected planes (vertical and horizontal) and lines for temperature visualization.

are presented graphically according to the horizontal and vertical planes as shown in Figure 6. Both planes are located in the middle of the uneven-span greenhouse dryer. Moreover, the temperature variation along lines 1 to 3 is evaluated in this section. Those lines are parallel to $z$-axis (east-west axis).

Figures $7(a)-7(d)$ show the air temperature distribution inside the greenhouse dryer in the horizontal and vertical planes for day-1 (Figures $7(\mathrm{a})$ and $7(\mathrm{~b})$ ) and day-2 (Figures $7(\mathrm{c})$ and $7(\mathrm{~d})$ ) at $13 \mathrm{~h}: 00$, respectively. The solar radiation level $\left(385 \mathrm{~W} / \mathrm{m}^{2}\right)$ of day- 1 at $13 \mathrm{~h}: 00$ was low compared to that of day-2. It can be observed in Figure 7(a) that the air temperature was high in the middle of the greenhouse dryer. Moreover, the areas near the floor had the highest temperature, while areas near the north wall are characterized by a low temperature (Figure 7(b)). This observation emphasizes the influence of the asphalt layer on the air temperature at low solar intensity. Similar results related to the influence of ground temperature on the air temperature within the greenhouse dryer were reported by Chauhan and Kumar [8]. In day-2, the solar radiation at $13 \mathrm{~h}: 00$ was the highest with a value of $647 \mathrm{~W} / \mathrm{m}^{2}$. The temperature distribution near the south wall and the ground was almost uniform compared to areas near the east and west walls (Figures 7(c) and 7(d)). This variation in temperature distribution and uniformity is due to solar radiation intensity and sun position in the sky.

Figures $8(\mathrm{a})$ and $8(\mathrm{~b})$ represent the air temperature variation inside the uneven-span greenhouse dryer at different locations along the $z$-axis over the horizontal plane. For both days, the temperature along all the lines increases until reaching the middle of the line and then it decreases. The maximum temperature of day- 1 was $48^{\circ} \mathrm{C}$ located in the middle of lines 2 and 3 while the lowest value was $39^{\circ} \mathrm{C}$ associated to places near the east and west walls of the greenhouse dryer over line 1 . In the case of day-2, the temperature values over line 3 are higher compared to lines 1 and 2 . The highest temperature was recorded in the middle of line 3 with a value of $58^{\circ} \mathrm{C}$, while the lowest value is located in the extremities of all the lines with a value of $47^{\circ} \mathrm{C}$.

In order to evaluate the simulated performance of the uneven-span greenhouse dryer, the simulated inside air temperatures during day- 1 and day- 2 were compared with the experimental data. Moreover, the root mean square percentage deviation $(e)$ and the correlation coefficient $(r)$ were evaluated as a tool for this comparison. Figures 9(a) and 9(b) show the comparisons between the calculated and measured air temperatures inside the greenhouse dryer for day- 1 and day-2, respectively. It is observed that the used CFD model underestimates the temperature at the first hours of the day for both days. However, calculated air temperatures are in reasonable agreement with the measured values. This result is validated by the values of $e$ and $r$ which were found to be equal to 6.37 and 0.97 and 8.17 and 0.94 for day- 1 and day2 , respectively. The highest temperature difference between the experimental and simulated data is found to be equal to $8.46^{\circ} \mathrm{C}$ at $10 \mathrm{~h}: 00$ for day- 1 and $8.23^{\circ} \mathrm{C}$ at $11 \mathrm{~h}: 00$ for day2 , while the lowest difference is found at $13 \mathrm{~h}: 00$ and $15 \mathrm{~h}: 00$ with a value of $0.80^{\circ} \mathrm{C}$ and $1.03^{\circ} \mathrm{C}$ for day- 1 and day-2, respectively. The difference between the experimental and CFD results at the beginning of the day can be attributed to the cumulated energy by the air within the greenhouse and the variation of the surrounding environmental parameters between the sunrise and the hour of measurements. In the second half of the day, the agreement between the two results is better. The small differences in this case can be due to the evolution of the environment parameters between each two successive hours, which were not taken into consideration in the CFD study. Furthermore, Vivekanandan et al. [9] and Khanlari et al. [13] found that the maximum average 
Temperature

contour 2

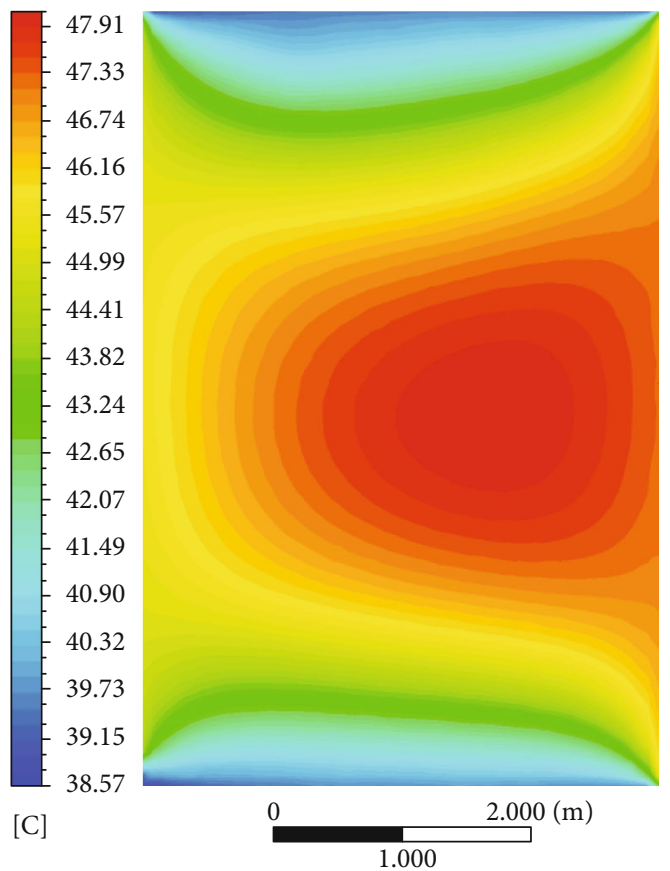

(a)
ANSYS

2020 R1

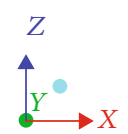

ANSYS

2020 R1 contour 1

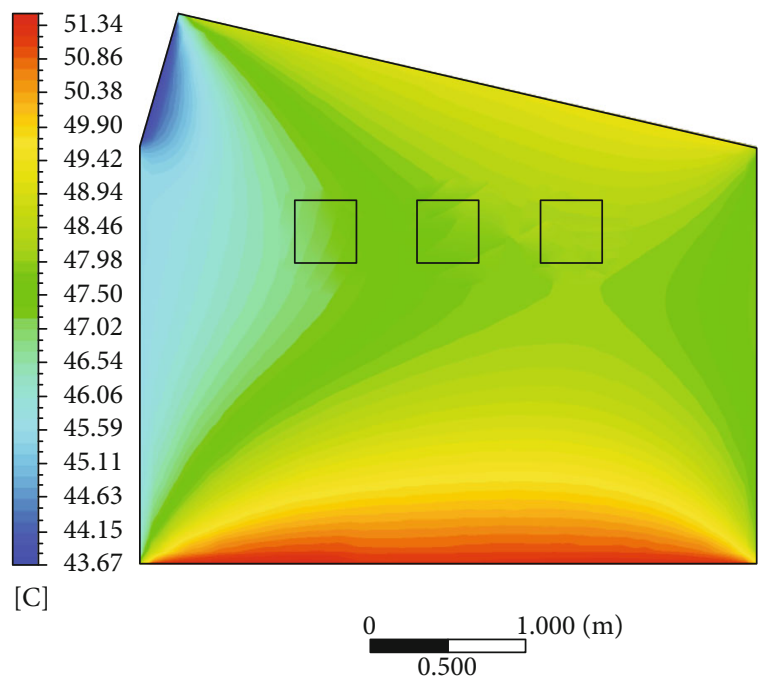

(b)

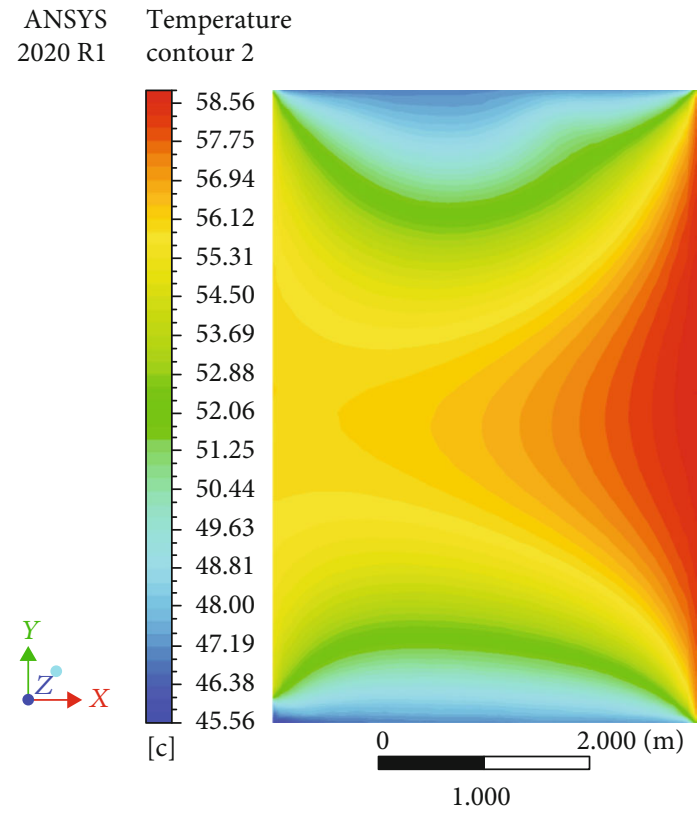

(c)

Figure 7: Continued. 


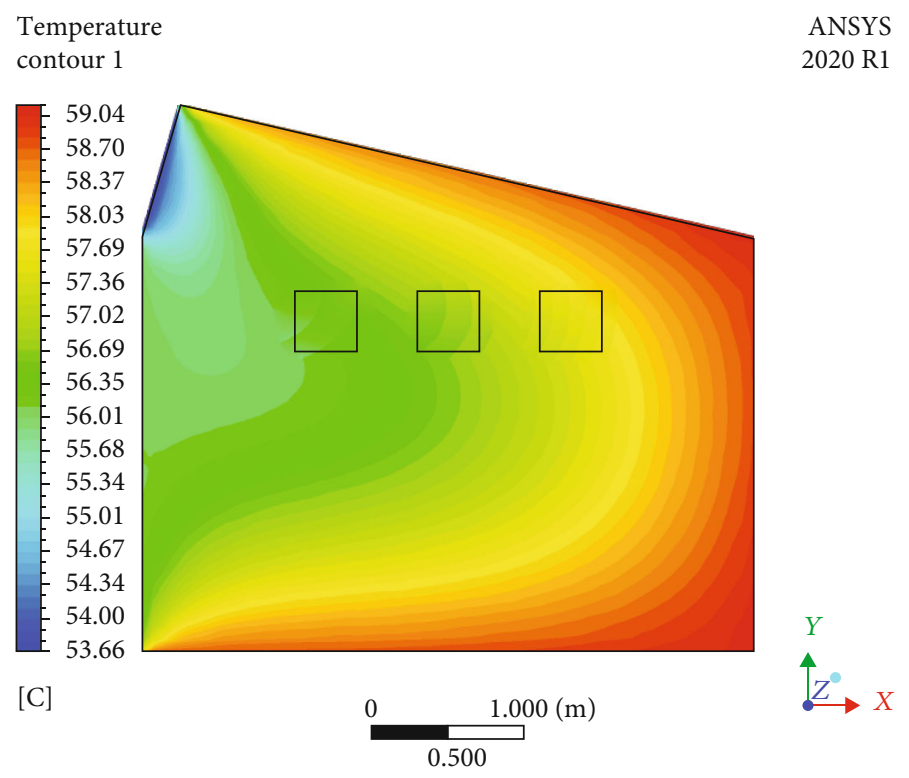

(d)

FiguRE 7: Temperature distribution inside the greenhouse dryer according to the horizontal and vertical planes for (a, b) day-1 and (c, d) day2 at $13 \mathrm{~h}: 00$.

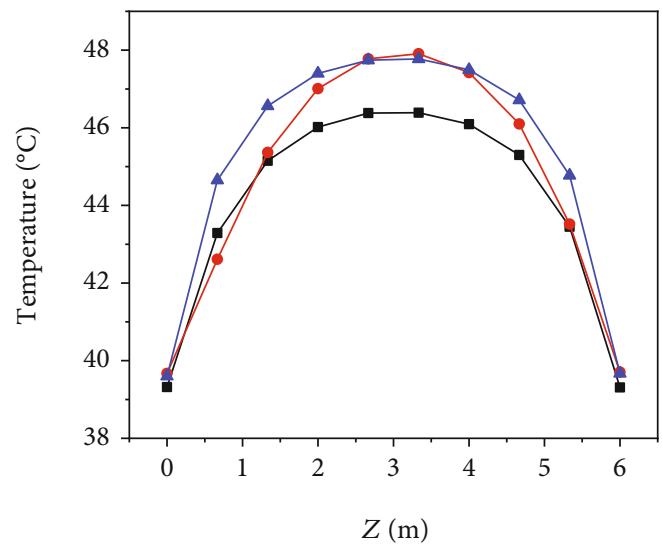

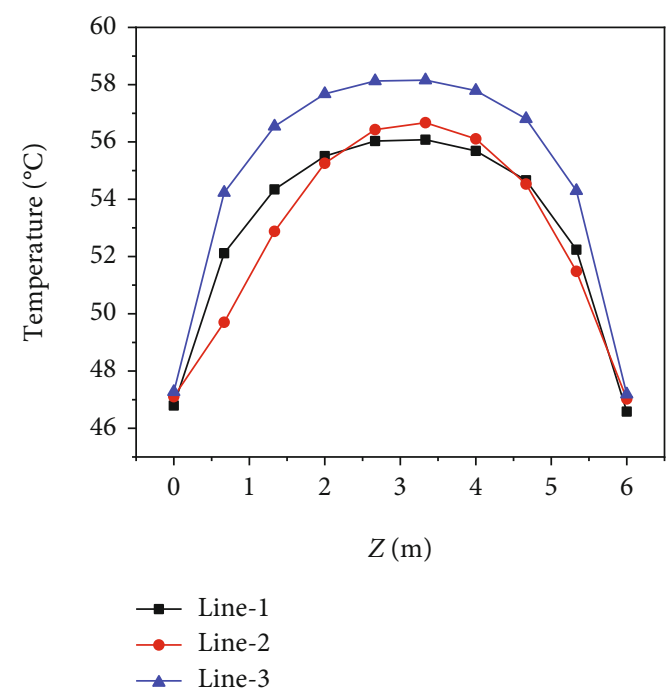

(b)

FIgURE 8: Temperature variation inside the greenhouse dryer according to lines 1 to 3 for (a) day-1 and (b) day-2.

temperature difference between the CFD simulation and measurement was $10^{\circ} \mathrm{C}$ and $3^{\circ} \mathrm{C}$, respectively. In the first study, the air temperature within the greenhouse was measured at one point in a small greenhouse, which is not the case in our study, where as a result of the large system size, the average temperature of 8 points is used. In the second study, on the other hand, the system was evaluated under forced convection, and the experimental and CFD temperature was measured at the outlet of the dryer. Consequently, these differences are within the acceptable limits in our case as stated by [14].
3.3. Performance Evaluation. The uneven-span greenhouse dryer performances under no-load conditions are evaluated in this section. Two main indictors are usually used:

(i) The Percentage of Net Heat Gain with Respect to Ambient Temperature $\left(Q_{g}\right)$. It is a widely used performance indicator for greenhouse systems. This parameter is defined as the ratio of the difference in temperatures of the air within the greenhouse $\left(T_{\mathrm{ag}}\right)$ and that of ambient $\left(T_{\text {ambiant }}\right)$ and the temperature of greenhouse air as follows [23]: 


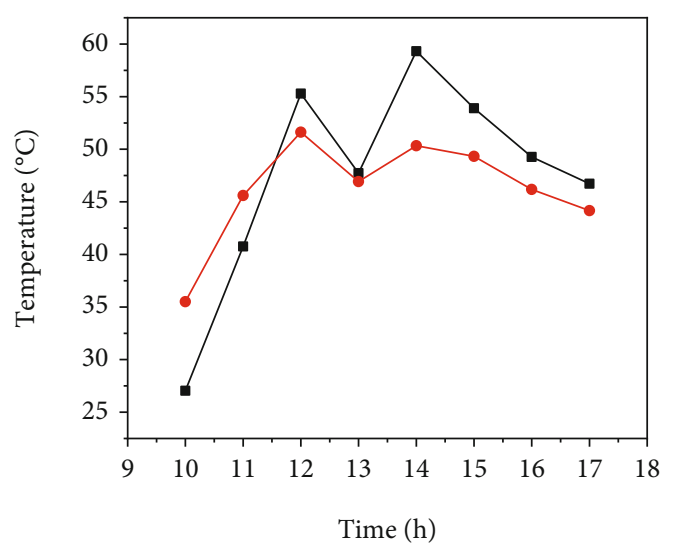

(a)

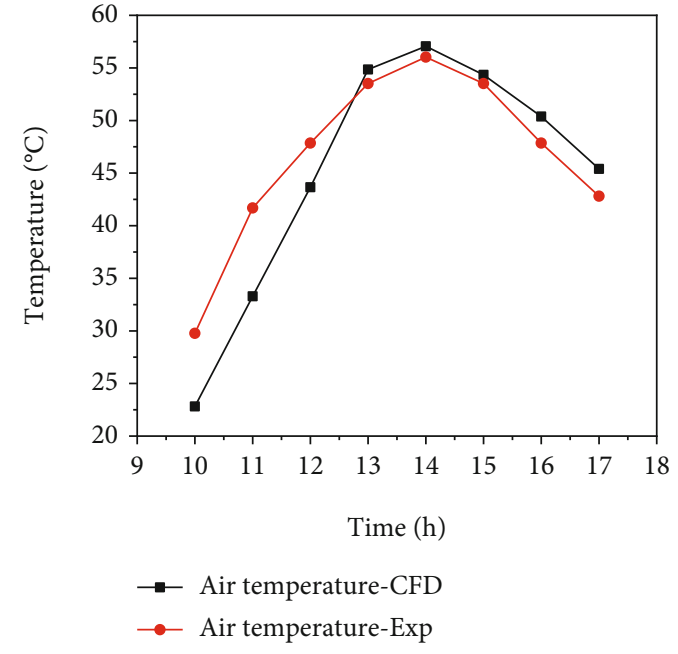

(b)

FIgURE 9: Comparison between the experimental and the simulation results of (a) day-1 and (b) day-2.

$$
Q_{g}=100 \frac{\left(T_{\mathrm{ag}}-T_{\mathrm{ambiant}}\right)}{T_{\mathrm{ag}}} .
$$

(ii) The instantaneous thermal loss efficiency factor $\eta_{i}$, developed by Sutar and Tiwari [24], is defined as the ratio of the overall all heat loss of the greenhouse dryer and the solar energy received by the greenhouse floor. It is calculated as follows [16]:

$$
\eta_{i}=\frac{U \sum A_{i}\left(T_{\mathrm{ag}}-T_{\mathrm{ambiant}}\right)}{I A_{\mathrm{gd}}}
$$

Figure 10 shows the variation of percentage of net heat gain inside the greenhouse dryer. Heat transferred to air within the greenhouse dryer plays an important role in increasing its temperature. Moreover, temperature is the most important factor which affects the dryer performance [19]. At an elevated inside air temperature, the drying rate will increase and the moisture removal will be more efficient [23]. In day-1, the percentage of net heat gain increases from $10 \mathrm{~h}: 00$ to $12 \mathrm{~h}: 00$ and then it starts decreasing, while in day-2, it increases from $10 \mathrm{~h}: 00$ to $11 \mathrm{~h}: 00$ and it stays steady until $15 \mathrm{~h}: 00$ then decreases. The highest value of the percentage of net heat gain at day- 1 and day- 2 was $52 \%$, while the lowest value was $40 \%$ and $39 \%$, respectively. In day-2, uniform and smooth curve shows the steady heat generation due to solar radiation intensity at the experiment site. Moreover, the average net heat gain during day- 1 and day- 2 was $46 \%$ and $48 \%$, respectively. The small difference of average value of net heat gain is $2 \%$, which shows the usefulness of covering the floor with asphalt.



FIgURe 10: Percentage of net heat gain for day-1 and day-2.

The instantaneous thermal loss efficiency factor refers to moisture removal rate inside the greenhouse dryer [16]. A higher rate of moisture removal leads to an increase in the drying rate of the products, which by consequence increases the dryer efficiency. Figures 11(a) and 11(b) show the characteristic curve for the uneven-span greenhouse dryer under no-load conditions for day-1 and day-2, respectively. The instantaneous thermal loss efficiency factor for the modified greenhouse dryer is similar to the results found by Prakash and Kumar [23] for a modified greenhouse dyer with different floor conditions, namely, barren floor, floor covered with black PVC sheet, and black painted floor. The average value of the instantaneous thermal loss efficiency factor is 0.52 and 0.44 , and it ranges between $0.35-0.85$ and $0.34-0.52$, for day- 1 and day-2, respectively. 


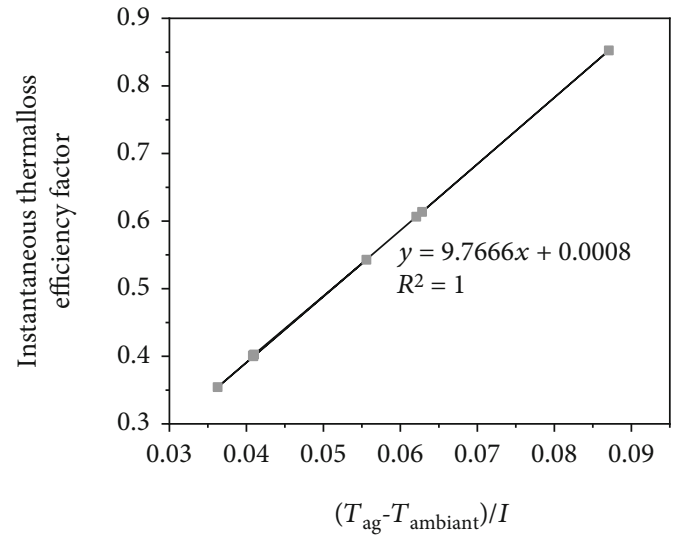

(a)

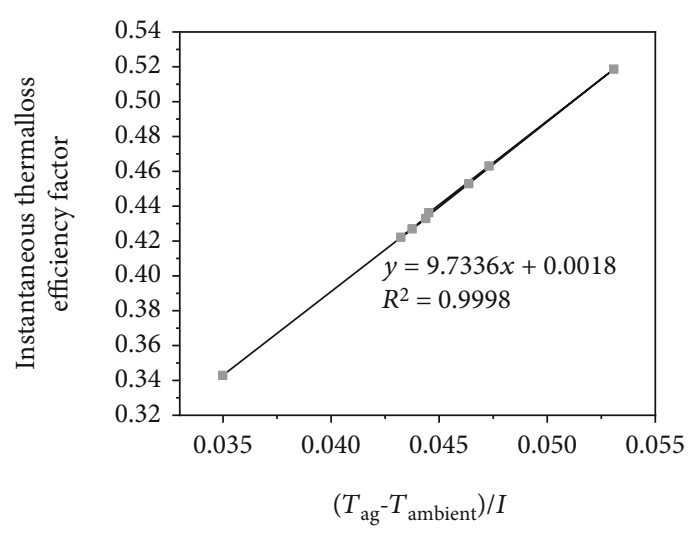

(b)

FIGURE 11: Characteristic curve for uneven-span greenhouse dryer at (a) day-1 and (b) day-2.

\section{Conclusion}

In this study, a modified uneven-span greenhouse dryer was studied numerically and experimentally. The comparison between the experimental and the simulation results was carried out for two distinct days of different weather conditions (solar radiation, ambient temperature and relative humidity, and wind speed). From the results, the following conclusions can be made:

(i) The inside air temperature and relative humidity are strongly related to the solar radiation and meteorological conditions of the site

(ii) The inside air temperature can reach more than $56^{\circ} \mathrm{C}$, and the relative humidity can go lower than $12 \%$

(iii) A good agreement is obtained between the computed and measured inside air temperature with a difference not exceeding $8.46^{\circ} \mathrm{C}$

(iv) The simulation results revealed the potential of asphalt as a covering material for the greenhouse floor in heating the inside air at low solar radiation

\section{Data Availability}

The data used to support the findings of this study are available from the corresponding author upon request.

\section{Conflicts of Interest}

The authors declare that they have no conflicts of interest.

\section{Acknowledgments}

This work was performed in the framework of the BIORESOL project. The authors are grateful to IRESEN for the financial support.

\section{References}

[1] P. Singh Chauhan, A. Kumar, and P. Tekasakul, "Applications of software in solar drying systems: a review," Renewable and Sustainable Energy Reviews, vol. 51, pp. 1326-1337, 2015.

[2] J. Chen, Y. Ma, and Z. Pang, "A mathematical model of global solar radiation to select the optimal shape and orientation of the greenhouses in southern China," Solar Energy, vol. 205, pp. 380-389, 2020.

[3] E. Tarigan, "Mathematical modeling and simulation of a solar agricultural dryer with back- up biomass burner and thermal storage," Case Studies in Thermal Engineering, vol. 12, pp. 149-165, 2018.

[4] A. Fudholi, B. Bakhtyar, H. Saleh, M. H. Ruslan, M. Y. Othman, and K. Sopian, "Drying of salted silver jewfish in a hybrid solar drying system and under open sun: modeling and performance analyses," International Journal of Green Energy, vol. 13, no. 11, pp. 1135-1144, 2016.

[5] S. Chouicha, A. Boubekri, D. Mennouche, and M. H. Berrbeuh, "Solar Drying of Sliced Potatoes. An Experimental Investigation," Energy Procedia, vol. 36, pp. 1276-1285, 2013.

[6] E. C. López-Vidaña, L. L. Méndez-Lagunas, and J. RodríguezRamírez, "Efficiency of a hybrid solar-gas dryer," Solar Energy, vol. 93, pp. 23-31, 2013.

[7] U. Çakır and E. Şahin, "Using solar greenhouses in cold climates and evaluating optimum type according to sizing, position and location: a case study," Computers and Electronics in Agriculture, vol. 117, pp. 245-257, 2015.

[8] P. S. Chauhan and A. Kumar, "Performance analysis of greenhouse dryer by using insulated north-wall under natural convection mode," Energy Reports, vol. 2, pp. 107-116, 2016.

[9] M. Vivekanandan, K. Periasamy, C. Dinesh Babu, G. Selvakumar, and R. Arivazhagan, "Experimental and CFD investigation of six shapes of solar greenhouse dryer in no load conditions to identify the ideal shape of dryer," Materials Today: Proceedings, vol. 37, pp. 1409-1416, 2021.

[10] N. F. Santos-Sánchez, R. Valadez-Blanco, M. S. GómezGómez, A. Pérez-Herrera, and R. Salas-Coronado, "Effect of rotating tray drying on antioxidant components, color and rehydration ratio of tomato saladette slices," LWT - Food Science and Technology, vol. 46, no. 1, pp. 298-304, 2012.

[11] A. M. Noh, S. Mat, and M. H. Ruslan, "CFD simulation of temperature and air flow distribution inside industrial scale solar 
dryer," Journal of Advanced Research in Fluid Mechanics and Thermal Sciences, vol. 45, no. 1, pp. 156-164, 2018.

[12] A. K. Babu, G. Kumaresan, V. Antony Aroul Raj, and R. Velraj, "CFD studies on different configurations of drying chamber for thin-layer drying of leaves," Energy Sources, Part A: Recovery, Utilization, and Environmental Effects, vol. 42, no. 18, pp. 2227-2239, 2020.

[13] A. Khanlari, A. Sözen, C. Şirin, A. D. Tuncer, and A. Gungor, "Performance enhancement of a greenhouse dryer: analysis of a cost-effective alternative solar air heater," Journal of Cleaner Production, vol. 251, p. 119672, 2020.

[14] P. Demissie, M. Hayelom, A. Kassaye, A. Hailesilassie, M. Gebrehiwot, and M. Vanierschot, "Design, development and CFD modeling of indirect solar food dryer," Energy Procedia, vol. 158, pp. 1128-1134, 2019.

[15] Y. Jia, C. Wang, C. Zhang, and W. Li, "Numerical modelling of radiation-convection coupling of greenhouse using underfloor heating," Open Journal of Fluid Dynamics, vol. 7, no. 3, pp. 448-461, 2017.

[16] O. Prakash and A. Kumar, "Design, development, and testing of a modified greenhouse dryer under conditions of natural convection," Heat Transfer Research, vol. 45, no. 5, pp. 433451, 2014.

[17] B. E. Launder and S. D. B., "MAN - ANSYS Fluent User' s Guide Releasde 15.0," Knowl. Creat. Diffus. Util., vol. 15317, pp. 724-746, 2013.

[18] S. Janjai, P. Intawee, J. Kaewkiew, C. Sritus, and V. Khamvongsa, "A large-scale solar greenhouse dryer using polycarbonate cover: Modeling and testing in a tropical environment of Lao People's Democratic Republic," Renewable Energy, vol. 36, no. 3, pp. 1053-1062, 2011.

[19] S. Tiwari and G. N. Tiwari, "Thermal analysis of photovoltaic thermal integrated greenhouse system (PVTIGS) for heating of slurry in potable biogas plant: an experimental study," Solar Energy, vol. 155, pp. 203-211, 2017.

[20] S. Tiwari and G. N. Tiwari, "Exergoeconomic analysis of photovoltaic-thermal (PVT) mixed mode greenhouse solar dryer," Energy, vol. 114, pp. 155-164, 2016.

[21] O. García-Valladares, N. M. Ortiz, I. Pilatowsky, and A. C. Menchaca, "Solar thermal drying plant for agricultural products. Part 1: direct air heating system," Renewable Energy, vol. 148, pp. 1302-1320, 2020.

[22] Y. I. Sallam, M. H. Aly, A. F. Nassar, and E. A. Mohamed, "Solar drying of whole mint plant under natural and forced convection," Journal of Advanced Research, vol. 6, no. 2, pp. 171-178, 2015.

[23] O. Prakash and A. Kumar, "Annual performance of a modified greenhouse dryer under passive mode in no-load conditions," International Journal of Green Energy, vol. 12, no. 11, pp. 1091-1099, 2015.

[24] R. F. Sutar and G. N. Tiwari, "Instantaneous thermal loss efficiency factor for summer greenhouse," International Journal of Solar Energy, vol. 18, no. 1, pp. 53-64, 1995. 